\title{
Evaluation of 657 cases of foreign body in the external ear canal
}

\author{
Rajendra K Teharia1* ${ }^{*}$, Nirmal C Purohit ${ }^{2}$
}

${ }^{1}$ Senior Resident, ${ }^{2}$ Assistant Professor, Department of Otorhinolaryngology, Jodhpur Medical College and hospitals, Jodhpur, INDIA. Email: drrajemdraent@yahoo.com

Abstract Background: The most common type of foreign body in otolaryngology is reported in the external ear. It may cause different complications like canal edema and laceration, tympanic membrane perforation, otitis externa and, difficult to remove. Object: Identify the age, sex, complications and types of foreign bodies in the external auditory canal. Method: This study was done in 657 cases presented in the otorhinolaryngology department of Jodhpur medical college and hospital and a Performa prepared and filled. Result: The most common type of external canal foreign body was insects. The most common age group was affected between 5-8 years and adults. School going children had maximum complications and need general anesthesia for removal. Conclusion: Incidence of external ear canal foreign bodies was very high in children as well as in adults. Complications were mostly seen in school going children and often require general anesthesia for removal.

Keywords: Foreign bodies, external auditory canal, school-going children.

\section{*Address for Correspondence:}

Dr Rajendra K Teharia, C-1402, Mangaldeep Apartment, near Pal Balaji Temple, Pal Road, Jodhpur (Rajasthan)-342008, INDIA.

Email: drrajemdraent@yahoo.com

Received Date: 04/05/2020 Revised Date: 13/06/2020 Accepted Date: 25/07/2020

DOI: https://doi.org/10.26611/10161531

This work is licensed under a Creative Commons Attribution-NonCommercial 4.0 International License. $(\propto c)$ ) EY-NC

\begin{tabular}{|l|l|}
\hline \multicolumn{2}{|c|}{ Access this article online } \\
\hline Quick Response Code: & Website: \\
& www.medpulse.in \\
& \\
\hline
\end{tabular}

\section{INTRODUCTION}

The foreign body in the external ear is a common ENT problem in emergencies ${ }^{1}$. The external ear foreign bodies are mostly reported in children and difficult to remove ${ }^{2}$. A small percentage of patients of external ear foreign bodies are needed general anesthesia to remove ${ }^{3}$. Rarely end aural incision is also required to remove the foreign body from the external ear ${ }^{4}$.

The complications are directly related to the type of foreign bodies involved and if they are not tackled rightly, the ear foreign bodies may lead to different complications like edema of canal and laceration, eardrum perforation, hearing loss, remaining foreign body. ${ }^{3,5,6}$ The main objective of our study was to identify the age, sex, types, and complications of foreign bodies in the external ear of the patients in all age groups presented in the otorhinolaryngology department of our hospital.

\section{MATERIALS AND METHOD}

This prospective observational study was done from September 2014 to March 2015 in 657 patients in the Department of Otorhinolaryngology of the tertiary care center in north Indian state of Rajasthan, India. Informed consent was obtained from all the patients who were enrolled in the study. Ethical clearance for the study was taken from the ethical committee. All patients with a history of foreign body in the external ear were included in the study and confirmed with Otoscopy. If no foreign body was found in the external ear on otoscopic examination that cases were excluded from the study.

\section{RESULTS}

A total of 657 foreign bodies of ear patients were analyzed as showed in Table-1. The most commonly affected age group was between 5-8 years of age (25.8\%) and above 16 years of age $(25.7 \%)$. The most common type of foreign bodies was insects $(19.9 \%)$, followed by seeds and beans $(14.8 \%)$ and stone $(14 \%)$. 
Table 1: Types of foreign body in the external ear by age and sex

\begin{tabular}{|c|c|c|c|c|c|c|c|c|c|c|c|}
\hline \multirow{2}{*}{$\begin{array}{c}\text { Types (\%) } \\
\text { Sex }\end{array}$} & \multicolumn{2}{|c|}{$0-4$ years } & \multicolumn{2}{|c|}{$5-8$ years } & \multicolumn{2}{|c|}{$9-12$ years } & \multicolumn{2}{|c|}{$\begin{array}{l}13-16 \\
\text { years }\end{array}$} & \multicolumn{2}{|c|}{$>16$ years } & \multirow[t]{2}{*}{ Total } \\
\hline & $\mathrm{M}$ & $\mathrm{F}$ & $M$ & $\mathrm{~F}$ & $M$ & $\mathrm{~F}$ & $M$ & $\mathrm{~F}$ & $M$ & $\mathrm{~F}$ & \\
\hline Insects (19.9\%) & 4 & 2 & 16 & 8 & 12 & 6 & 12 & 6 & 35 & 30 & 131 \\
\hline Seeds sand beans ( $14.8 \%)$ & 5 & 2 & 30 & 12 & 20 & 8 & 10 & 5 & 5 & 0 & 97 \\
\hline Stones $(14 \%)$ & 8 & 8 & 10 & 8 & 16 & 8 & 12 & 6 & 8 & 8 & 92 \\
\hline Cotton pieces (12.9\%) & 4 & 2 & 14 & 6 & 16 & 8 & 5 & 2 & 2 & 8 & 85 \\
\hline Wood pieces (12.6\%) & 7 & 5 & 10 & 8 & 12 & 12 & 8 & 7 & 7 & 7 & 83 \\
\hline Ornaments parts (10.5\%) & 10 & 8 & 12 & 8 & 6 & 4 & 5 & 3 & 8 & 5 & 69 \\
\hline Paper pieces (4.8\%) & 2 & 0 & 6 & 4 & 5 & 4 & 1 & 0 & 4 & 6 & 32 \\
\hline Rubber pieces (3.2\%) & 2 & 0 & 4 & 4 & 4 & 3 & 0 & 0 & 2 & 2 & 21 \\
\hline Miscellaneous (peanuts, polythenes, polymers) (7.2\%) & 6 & 4 & 5 & 5 & 5 & 5 & 0 & 3 & 10 & 4 & 47 \\
\hline \multirow[t]{2}{*}{ Total } & 48 & 31 & 107 & 63 & 96 & 58 & 53 & 32 & 99 & 70 & \\
\hline & \multicolumn{2}{|c|}{79} & \multicolumn{2}{|c|}{170} & \multicolumn{2}{|c|}{154} & \multicolumn{2}{|c|}{85} & \multicolumn{2}{|c|}{169} & 657 \\
\hline
\end{tabular}

In Table-2, the most common complication due to foreign bodies in the ear was canal edema and laceration (58.87\%), and the commonly affected age group was between $0-8$ years of age (64\%). Most complications in foreign bodies in the external ear were due to insects $(38 \%)$, beans and seeds $(25.4 \%)$, and stones $(20.6 \%)$ as shown in Table-3. 76 cases were needed removal under general anesthesia. The most common age group which needed general anesthesia for external ear foreign bodies was between $0-8$ years $(60.5 \%)$ and the most common type of foreign body which needed general anesthesia was stone $(39.5 \%)$ as showed in Table-4 and 5.

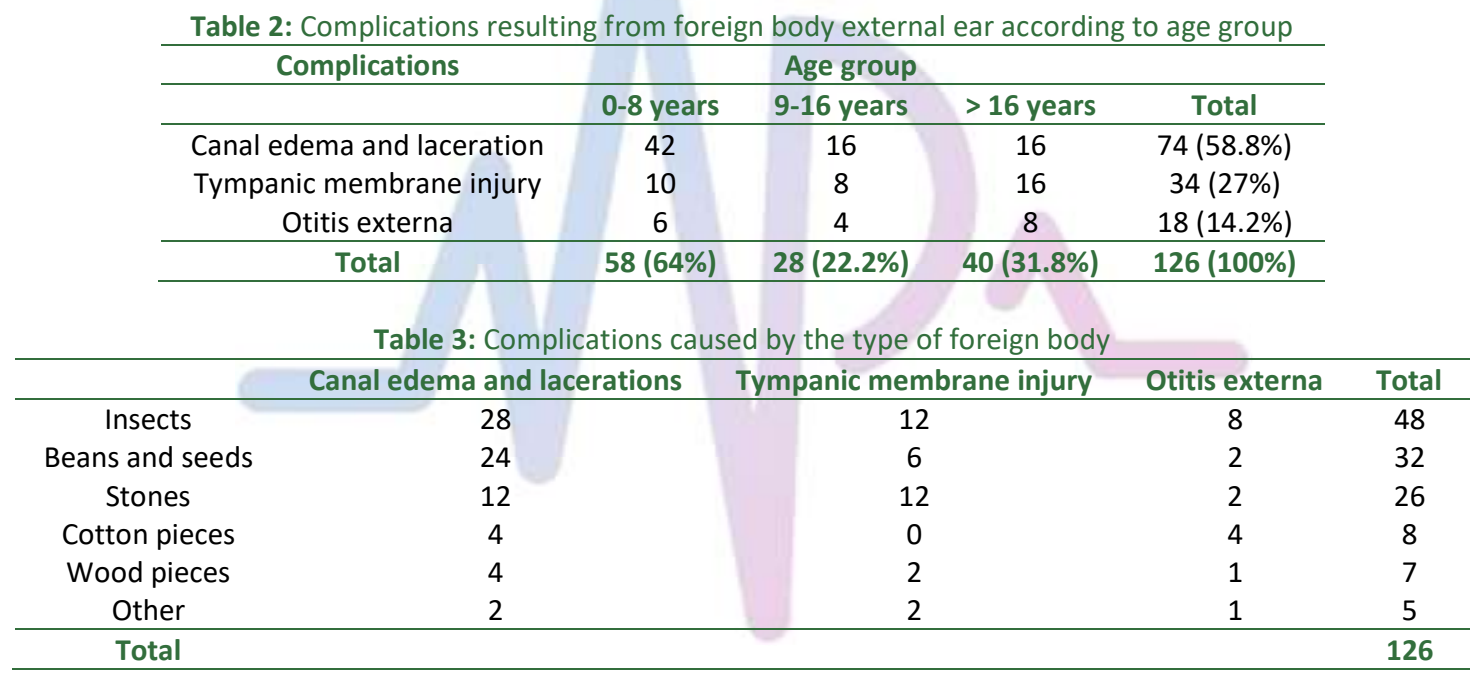

Table 4: Age group wise distribution of general anesthesia usage

\begin{tabular}{cc}
\hline Age group & General Anesthesia usage $(\%)$ \\
\hline $0-8$ years & $46(60.5 \%)$ \\
$9-16$ years & $16(21 \%)$ \\
$>16$ years & $14(18.5 \%)$ \\
\hline Total & $76(100 \%)$ \\
\hline
\end{tabular}

Table 5: foreign body types wise distribution for general anesthesia usage

\begin{tabular}{cc}
\hline Types of foreign body & No. of case (\%) \\
\hline Insects & $4(5.2 \%)$ \\
Beans and seeds & $6(7.9 \%)$ \\
Stones & $30(39.5 \%)$ \\
Cotton pieces & $2(2.6 \%)$ \\
Wood pieces & $8(10.5 \%)$ \\
Miscellaneous & $26(34.3 \%)$ \\
\hline Total & $76(100 \%)$ \\
\hline
\end{tabular}




\section{DISCUSSION}

Foreign body in the external ear is a common cause of emergencies in hospitals. The causes of ear foreign body in the ear may be due to accidental insertion of objects, the curiosity of children to put inside ear during playing, attempt to clear wax to maintain local hygiene of ear, itching ear with cotton bud especially by adults of their ear. In our study, maximum cases occurred in the age group between 5-8 years of age. This may be due to accidental entry in-ear during playing by themselves or by mates or due to the curiosity of children. The second most commonly affected group of external ear foreign bodies was above 16 years of age. This may be due to accidental insertion during local cleaning to maintain ear hygiene or during ear itching. Accidental insertion of ear foreign bodies in adults by their children during playing or during the sleeping of parents while their children were playing nearby, was an interesting cause also present in some cases in our study. The most common age group affected by complications of foreign body in the ear was between $0-8$ years $(64 \%)$. This may be due to inappropriate manipulation of the ear canal by parents, untrained general practitioners, and by uncooperative nature of children ${ }^{7}$. In our study, the most common foreign body ear types were insects $(19.9 \%)$, seeds and beans $(14.8 \%)$, and stones (14\%), comparable with the study done by Bressler and Shelton. ${ }^{7}$ Insects were more common in adults and younger age groups compared to stones, seeds, and beans which were more common in school going children age groups. This may be due to the adult population is more mobile and children are more curious or accidental insertion occur during playing. Ornamental pieces were very common below 4 year of age children this may be due to their nearness to parents or habit of playing with parents ornaments $^{8}$. The most common type of foreign body ear causing complications in-ear was insects $(38.1 \%)$, beans (25.4\%), and stones (20.7\%). This may be due to the nature of foreign body and history of attempts of removal and improper technique of removal of foreign body ear ${ }^{9}$. Only $11.6 \%$ of cases in our study were required general anesthesia and the most common type of foreign body ear was stones $(39.5 \%)$ that needed general anesthesia for removal ${ }^{[3,10}$. The most common complications due to ear foreign body in our study were canal laceration (58.8\%)followed by tympanic membrane perforation
(27\%) and otitis externa (14.2\%), comparable to study done by Neto et al. ${ }^{11}$.

\section{CONCLUSION}

In our study, the external ear foreign bodies were most frequent in school going children age group and in adults. The most common types of ear foreign bodies were insects followed by seeds and beans and stones respectively. The complication in-ear foreign body was the most common inbetween age group 0-8 years. Complications were the most frequent in insets, seeds, and beans, and stones ear foreign bodies. Stones ear foreign bodies mostly required general anesthesia for removal because of their nature.

\section{REFERENCES}

1. Mackle T, Conlon B. Foreign bodies of the nose and ears in children; should theses be managed in the accidental and emergency setting? International Journal of Pediatric Otorhinolaryngology. 2006, 70(3):425-428

2. Bento RF et al.. Corpos Estranhos. In: Bento RF.et al. Tratado de Otologia. Sao Paulo: Fundacao Otorinolaringologia;1998, 153-155

3. Balbani APS, Sanchez TS, Butugan O, Kii MA, Angelico Jr FV, Ikino CMY, D'Antonio WEP. Ear and nose foreign body removal in children. International Journal of Pediatric Otorhinolaryngology. 1998, 46 (1):37-42

4. Engelsma RJY, Lee WC. Case Report, Impacted aural foreign body requiring endaural incision and canal widening for removal. International Journal of Pediatric Otorhinolaryngology. 1998, 44(2):18-23

5. Schulze SL, Kerschner J, Beste D. Pediatric external auditory canal foreign bodies: a review of 698 cases. Otolaryngol Head Neck Surg. 2002, 127(1):73-79

6. Kojima H, Tanaka Y, Mori E, Uchimizu H, Moriyama H. Penetrating vestibular injury due to a twig entering via the external auditory meatus. American Journal of Otolaryngology. 2006, 27(6):418-42

7. Bressler and Shelton C. Ear foreign body removal: Review of 98 consecutive cases. Laryngoscope 1993; 103: 367370

8. Das SK. Aetiological evaluation of foreign bodies in the ear and nose. J Laryngol Otol 1984; 98: 989-99

9. Ansley JF, Chunningham MJ. Treatment of Aural Foreign bodies in Children. Pediatrics 1998, 101 (4): 638-641.

10. Jensen JH. Technique for removing a spherical foreign body from the nose and ear. Ear nose Throat J 1976; 55: 270-271

11. Neto JJS, Lima JCB, Vitale RF, Geminiani RJ. Corpos Estranhos em Otorrinolaringologia - Levantamento do Hospital Monumentoe Clinica Otorhinus. Arq Int Otorrinolaringol. 2007, 11(3): 305-310.



Policy for Articles with Open Access:

Authors who publish with MedPulse International Journal of ENT (Print ISSN: 2579-0854) (Online ISSN: 2636-4727) agree to the following terms: Authors retain copyright and grant the journal right of first publication with the work simultaneously licensed under a Creative Commons Attribution License that allows others to share the work with an acknowledgement of the work's authorship and initial publication in this journal.

Authors are permitted and encouraged to post links to their work online (e.g., in institutional repositories or on their website) prior to and during the submission process, as it can lead to productive exchanges, as well as earlier and greater citation of published work. 